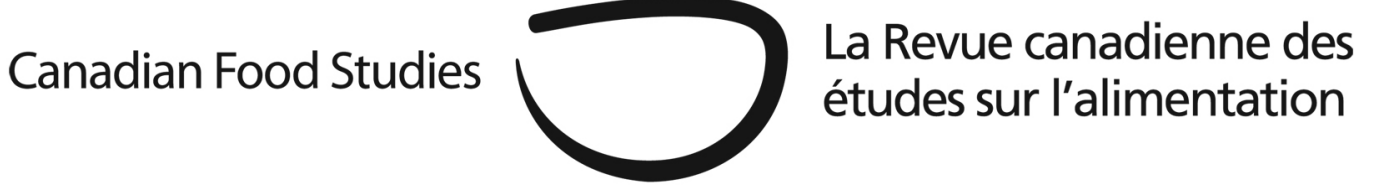

\title{
Commentary
}

\section{Borders, boundaries, and becoming food studies: Looking back, pushing forward}

Jennifer Brady, ${ }^{1}$ Charles Z. Levkoe, ${ }^{2}$ and David Szanto ${ }^{3}$

1 PhD Candidate, Queens University

2 Postdoctoral Fellow, Wilfrid Laurier University

3 Master Program Director, University of Gastronomic Sciences

On May 25, 2014, at the ninth annual assembly of the Canadian Association for Food Studies (CAFS), we (the authors) organized a plenary panel that assembled a number of leading food scholars from across North America to reflect on the current state of food studies. This commentary brings together the perspectives from the presentations as well as our own thoughts and ideas. We aim to consider some of the trajectories and intersections of food studies as a field, as well as the spaces and boundaries that it might occupy and transgress.

In 2008, Food, Culture \& Society published a special issue focusing on food scholarship in Canada. It opened with a commentary written by Elaine Power and Mustafa Koç that addressed the emerging field of food studies and the emergence of CAFS as a national research association of both scholars and practitioners. In the article, they explained that the inaugural idea behind CAFS was "to contribute to interdisciplinary scholarship addressing the complex relationships and interconnections between food related issues" (p. 264). They also celebrated CAFS members who were engaged in both theory-centred research as well as work focused on the practical implications for civil society and policy makers. Power and Koç discussed the way that using food as a framework to interrogate social, economic, and ecological realities could help to understand who we are as Canadians. They wrote: "In particular, Canadians eat doughnuts (not donuts), more doughnuts per capita than any other country in the world.... In the contemporary Canadian imaginary, the doughnut is connected to a specific chain, Tim Hortons, where the standard "double-double" will get you a coffee with two creams and two sugars, in 
case your sweet, fatty doughnut treat is not sweet and fatty enough” (p. 265). They rightly argued that food connects us and divides us, creating boundaries and identities.

In the decade since the establishment of CAFS, much has changed. Food studies has matured from a disparate collection of individuals into a vibrant field of study that includes numerous academic and non-academic associations, journals, magazines, blogs, programs of study, and an ever-expanding interdisciplinary literature. As an association, CAFS now comprises hundreds of members from across the country (and around the globe), an increasingly dynamic annual assembly, a board of directors including leading academics and practitioners, and of course this journal, Canadian Food Studies/La Revue canadienne des études sur l'alimentation, launched in 2014. Despite, or perhaps because of these accomplishments, a series of new questions arise for CAFS members, as well as for the field of food studies more broadly.

Koç, Sumner, and Winson (2012) have written, "food studies is a relatively new field of research and scholarship that focuses on the web of relations, processes, structures, and institutional arrangements that cover human interaction with nature and other humans involving the production, distribution, preparation, consumption, and disposal of food” (p. xii). However, they go on to note, "defining the boundaries of food studies is a challenging task." A number of years earlier, Warren Belasco (2008) advised, "it may be premature to announce the birth of a new discipline” (p. 5). Taken together, these observations imply that defining or delimiting food studies may be problematic, but they also suggest that constructing a framing structure around food scholarship may be wrong-headed in the first place. Indeed, part of what makes exploring food so exciting is the diversity of perspectives and approaches involved. This diversity is clearly a strength and a rich source of potential futures for food studies, but it also presents those involved in food scholarship with a variety of challenges, both institutional and individual.

As a national interdisciplinary association, CAFS aims to promote a critical and progressive space that welcomes a diversity of people engaged in food-related research. Nonetheless, it still mirrors the ideals of its founders, privileging a focus on social sciences and food systems sustainability. There has been far less participation from those working in the humanities, the various area studies (e.g., gender, media, cultural), art, design, and technology, and the pure and applied sciences. While the annual conference has become a place that fosters greater inclusivity (though the Exploration Gallery, innovative session formats, joint-listed sessions, and special events), there is still much work to do in order to explicitly transgress historic boundaries and actively promote more cross-disciplinary participation.

Six years after Power and Koç riffed on the iconic Canadianness of Tim Hortons, the doughnut chain has been acquired by transnational giant, Burger King Worldwide Inc. (It is actually the second time Tim's has been owned by a non-Canadian company: Wendy's purchased the business in the early 1990s.) While the business deal may ultimately benefit the Canadian economy more than our national identity (Brownell, 2014), it again raises questions about what is Canadian, what defines us as a food culture, and what Canadian food scholars' roles will become in the future. 
The plenary panel at the 2014 CAFS conference brought together six panelists from a range of disciplinary perspectives, in order to present a diversity of thinking on the current state of food studies. Taking a cue from the 2014 Congress of the Humanities and Social Sciences theme, we titled the session "Borders, Boundaries, and Becoming Food Studies: Looking Back, Pushing Forward.” The intent was to generate a conversation among panellists and audience members about food studies itself_-its edges and limits, but also the past, present, and future identity of the field. Ultimately, we hoped that these ideas would extend throughout the conference and inspire the thinking and work of the food studies community in the years to come. The six panellists included: Jessica Mudry, Ryerson University; Kathleen LeBesco, Marymount Manhattan College; Josée Johnston, University of Toronto; Rachel Engler-Stringer, University of Saskatchewan; Elaine Power, Queen's University; and Abra Brynne, Food Secure Canada. Each presenter was asked to respond to three questions in their opening remarks: (1) What does the term "food studies" mean to you? (2) Is food studies distinct from other fields? (3) What should food studies encompass? We have identified three key themes that emerged from the panellists' remarks and the discussion that followed.

The first of these themes set out an aspirational vision for the field and addressed what food studies should be or, more specifically, what it should strive to be. Elaine Power reminded us that CAFS was founded by an energetic and collegial network of scholars and activists who recognized the inherent nurturing aspects of food, love, and belonging, and who also cared passionately about the role of food in making the world a better place to live. At the same time, because food is inherently social and political, even as we theorize about how food makes us collectively, we must also allow ourselves to be drawn out of the ivory tower to participate in those collectives. As Rachel Engler-Stringer declared, “food studies is a call to action,” a space in which participation and reflexivity can make food more accessible, equitable, sustainable, environmentally conscientious, and socially just.

A second key theme brought to light the inherent frictions that exist within the field of food studies. The main tension, addressed by several panellists, concerned the interdisciplinary nature of food studies. Questions were raised: Are food studies now, or should they aim to be, either multidisciplinary or interdisciplinary? If so, what challenges and opportunities arise? While some participants cited the benefit of resisting disciplinarity, others raised points about the risk of being perceived as too undefined in an otherwise discipline-structured academy, including for emerging scholars looking for post-doctoral positions, research, and/or faculty positions. A discussion emerged about the need and potential to create alternative academic structures to facilitate the distinctive types of interdisciplinary, and even transdisciplinary work that many in food studies do or aspire to do. What might these alternative structures look like? How do we create a unity of intellectual frameworks and integrated perspectives that deal with the extensive nature of food? Another related tension revealed the potential conflict between food studies’ growth and continued recognition — what might be seen as its professionalization —and the field's political commitments. How do we navigate the need, and perhaps desire, to grow and professionalize food studies with the progressive politics that undergird the field? 
Finally, a third theme exhorted the food studies community to view the contradictions and tensions within food studies as a space of opportunity, rather than a barrier to future vitality. Abra Brynne urged participants to think in terms of plurality and ecological collaborationdiversity as a source of resilience. This message was perhaps most inspirationally illustrated through her analogy of orchards. In most conventional orchards, dead zones surround the base of each trunk; nothing grows except the fruit trees that are carefully "protected” using a mixture of chemical and human resources. In contrast, under the canopy of an organic orchard lies a vital and lush ecosystem of grasses, native plants, birds, and insects that sustains the life of the trees and the balance within the whole. If we are to encourage food studies to thrive within the academy, Brynne suggested, then we must do so while supporting disciplinary diversity and a collaborative set of relationships with other academic "species."

In her comments, Josée Johnston expressed the need to make connections between political-economic issues, such as globalized commodity chains, sociological issues such as gender inequality, food justice issues like food insecurity, and ecological ones like the need for sustainable food systems. In previous work, Johnston (2008) has asserted that this kind of multidisciplinarity is important to a food studies that "resists ossification and maintains relevance in a university setting” (p. 271). She also notes the serious challenges that sometimes unyielding disciplinary structures present to those wishing to do multidisciplinary work, which raises questions about the capacity for food studies to continue within its somewhat blurry boundaries.

We as authors would also like to point out that bridging disciplinary perspectives asks food studies scholars and practitioners to traverse not just disciplinary boundaries, but epistemological ones. Crossing epistemological boundaries means that we must revisit not only how and what we study, but also the underlying frameworks that structure our understanding of knowledge. This implicates not just interdisciplinary approaches to food scholarship, but interepistemological ones as well (Brady, Millious \& Ventresca, forthcoming). Murphy (2011) notes that a superficial "downstream” approach to multi- or interdisciplinary work is the norm, in which data collection and knowledge dissemination may reflect multiple perspectives, but the research is undergirded by a single dominant epistemic paradigm. An inter-epistemological approach in food studies asks that researchers interrogate the early "upstream" stages of planning - theoretical assumptions, development of research questions and methodologiesthose fundamental paradigms that frame the research at its outset. Taking such an approach is key to unlocking potentially revolutionary modes of doing food-related work, as well as bringing about revelations within our existing paradigms. In food studies specifically, an emphasis on inter-epistemological approaches would allow the food studies community to better integrate and learn from the work that scholars in the natural sciences, arts, and humanities do, as well that of the activists, students, and community members who are also important stakeholders in the field. Food studies can thus invite us to reflect on what we do and how we do things, but also how we understand what it is that we are doing, and why. Put simply, how do we know and come to know with, through, and about food? 
Ultimately, the challenges and tensions raised here may not be addressed within food studies in our lifetimes, and perhaps this is a good thing. A system that is constantly in a state of inquiry and investigation, navigation and negotiation, is a system that evolves and responds to the state of the world of which it is part. If there is one concluding recommendation that we might propose with this commentary, it is to remain attentive to these movements and actively continue the processes of critical exchange and reflection that many food communities now embrace, both within and outside of academic settings.

\section{References}

Belasco, W. (2008). Food: The key concepts. New York: Bloomsbury.

Brady, J., Millious, V. \& Ventresca, M. (forthcoming). Problematizing milk: Considering production beyond the food system. Manuscript in preparation.

Brownell, C. (2014). Tim Hortons holds the 'real power' in Burger King deal, says industry expert. Financial Post. Accessed September 21, 2014 at http://business.financialpost.com/2014/08/25/tim-hortons-burger-king-takeover/.

Johnston, J. (2008). Struggles for the 'up and coming': Challenges facing new food scholars and food scholarship. Food, Culture \& Society, 11(3), 269-74.

Koç, M., Sumner, J., \& Winson, A. (2012). Critical perspectives in food studies. Toronto: Oxford.

Murphy, B. L. (2011). From interdisciplinary to inter-epistemological approaches: Confronting the challenges of integrated climate change research. The Canadian Geographer, 55(4), 490-509.

Power, E., \& Koç, M. (2008). A double-double and a maple-glazed doughnut. Food Culture and Society, 11(3), 1-5. 